\title{
No evidence for amyloid pathology as a key mediator of neurodegeneration post- stroke - a seven-year follow-up study
}

Guri Hagberg ${ }^{1,2^{*}}$ (D) Hege Ihle-Hansen ${ }^{1,3}$, Brynjar Fure ${ }^{4}$, Bente Thommessen ${ }^{5}$, Håkon Ihle-Hansen 1,2, Anne Rita Øksengård ${ }^{1}$, Mona K. Beyer ${ }^{6}$, Torgeir B. Wyller ${ }^{2,3}$, Ebba Gløersen Müller ${ }^{7,2}$, Sarah T. Pendlebury ${ }^{8,9}$ and Per Selnes ${ }^{5,2}$

\begin{abstract}
Background: Cognitive impairment $(\mathrm{Cl})$ with mixed vascular and neurodegenerative pathologies after stroke is common. The role of amyloid pathology in post-stroke $\mathrm{Cl}$ is unclear. We hypothesize that amyloid deposition, measured with Flutemetamol ( ${ }^{18} \mathrm{~F}$-Flut) positron emission tomography (PET), is common in seven-year stroke survivors diagnosed with $\mathrm{Cl}$ and, further, that quantitatively assessed ${ }^{18} \mathrm{~F}$-Flut-PET uptake after 7 years correlates with amyloid- $\beta$ peptide $\left(A \beta_{42}\right)$ levels in cerebrospinal fluid (CSF) at 1 year, and with measures of neurodegeneration and cognition at 7 years post-stroke.

Methods: 208 patients with first-ever stroke or transient Ischemic Attack (TIA) without pre-existing Cl were included during 2007 and 2008. At one- and seven-years post-stroke, cognitive status was assessed, and categorized into dementia, mild cognitive impairment or normal. Etiologic sub-classification was based on magnetic resonance imaging (MRI) findings, CSF biomarkers and clinical cognitive profile. At 7 years, patients were offered ${ }^{18} \mathrm{~F}$-Flut-PET, and amyloid-positivity was assessed visually and semi-quantitatively. The associations between ${ }^{18}$ F-Flut-PET standardized uptake value ratios (SUVr) and measures of neurodegeneration (medial temporal lobe atrophy (MTLA), global cortical atrophy (GCA)) and cognition (Mini-Mental State Exam (MMSE), Trail-making test A (TMT-A)) and CSF $A \beta_{42}$ levels were assessed using linear regression.
\end{abstract}

Results: In total, 111 patients completed 7-year follow-up, and 26 patients agreed to PET imaging, of whom 13 had CSF biomarkers from 1 year. Thirteen out of 26 patients were diagnosed with Cl 7 years post-stroke, but only one had visually assessed amyloid positivity. CSF A $\beta_{42}$ levels at 1 year, MTA grade, GCA scale, MMSE score or TMT-A at 7 years did not correlate with ${ }^{18} \mathrm{~F}$-Flut-PET SUVr in this cohort.

Conclusions: Amyloid binding was not common in 7-year stroke survivors diagnosed with Cl. Quantitatively assessed, cortical amyloid deposition did not correlate with other measures related to neurodegeneration or cognition. Therefore, amyloid pathology may not be a key mediator of neurodegeneration 7 years post-stroke.

Trial registration: Clinicaltrials.gov (NCT00506818). July 23, 2007. Inclusion from February 2007, randomization and intervention from May 2007 and trial registration in July 2007.

Keywords: Stroke, Cognitive impairment, Cerebrospinal fluid, Positron emission tomography, Prognosis

\footnotetext{
* Correspondence: guri.hagberg@gmail.com

'Bærum Hospital, Vestre Viken Hospital Trust, N-3004 Drammen, Norway

${ }^{2}$ Institute of Clinical Medicine, University of Oslo, Oslo, Norway

Full list of author information is available at the end of the article
}

(C) The Author(s). 2020 Open Access This article is licensed under a Creative Commons Attribution 4.0 International License, which permits use, sharing, adaptation, distribution and reproduction in any medium or format, as long as you give appropriate credit to the original author(s) and the source, provide a link to the Creative Commons licence, and indicate if changes were made. The images or other third party material in this article are included in the article's Creative Commons licence, unless indicated otherwise in a credit line to the material. If material is not included in the article's Creative Commons licence and your intended use is not permitted by statutory regulation or exceeds the permitted use, you will need to obtain permission directly from the copyright holder. To view a copy of this licence, visit http://creativecommons.org/licenses/by/4.0/ The Creative Commons Public Domain Dedication waiver (http://creativecommons.org/publicdomain/zero/1.0/) applies to the data made available in this article, unless otherwise stated in a credit line to the data. 


\section{Background}

Post-stroke cognitive impairment (CI) is caused by both vascular and neurodegenerative changes [1], and as Alzheimer disease (AD) accounts for $50-70 \%$ of all dementia cases [2], the role of AD pathology are important to address in CI post-stroke. Due to an aging population and a decline in post-stroke mortality, strategies for timely diagnosis and disease prevention are urgently needed [3-6]. Post-stroke cognitive impairment follows different trajectories, and risk scores based on clinical and neuroimaging variables are promising $[7,8]$, but do not include amyloid biomarkers. Amyloid positivity has been associated with more severe cognitive decline poststroke in small studies $[9,10]$, and might be included in future prediction models and personalized management.

Known risk factors for dementia in the general population include neuroimaging variables such as $\beta$-amyloid deposition, medial temporal lobe atrophy (MTLA), and small vessel disease. The risk factors are additive, and there are several indications of mechanistic interactions $[11,12]$. Recent studies support the use of amyloid positron emission tomography (PET) in patients with uncertain diagnosis in a memory clinic setting [13-15], but such studies are missing in the post-stroke population. Biomarkers of cortical amyloid deposition include cerebrospinal fluid (CSF) Amyloid- $\beta$ peptide $\left(A \beta_{42}\right)$ levels and amyloid-binding PET tracers. CSF $A \beta_{42}$ levels are established biomarkers of Alzheimer's disease, and constitute the central biomarker for amyloid plaque formation [16]. ${ }^{18}$ F-Flutemetamol $\left({ }^{18}\right.$ F-Flut) is increasingly used in dementia diagnostics, as it exhibits high affinity binding for fibrillary amyloid $[17,18]$. A negative ${ }^{18} \mathrm{~F}$ Flut-PET examination indicates sparse or no fibrillar amyloid, incompatible with a neuropathological diagnosis of AD [19]. ${ }^{18}$ F-Flut-PET and CSF $A \beta_{42}$ levels are inversely highly correlated $[15,20-22]$. In animal models, there has been a synergistic relationship between inflammation induced by stroke-related ischemia and $\beta$ amyloid deposits [23-25], but this association has not been studied in humans [26, 27]. Amyloid deposition increases with age [12], and theoretically might accelerate due to inflammation related to stroke. Quantitative assessment of amyloid PET allows a continuous approximation of amyloid plaques in different cortical regions and might be more informative than binary visual assessments. MTLA and cortical atrophy are well described in both $\mathrm{AD}$ and pure cerebrovascular disease [28-30], but there is still no consensus regarding the contribution of amyloid pathology to post-stroke neurodegeneration and cognitive impairments [31-33]. A recent study from Pendlebury et al. shows that Apolipoprotein E $\varepsilon 4$ genotype, a known risk factor for AD linked to failure in amyloid clarence [34], is associated with increased risk of dementia after stroke [35].
The Atherosclerosis Risk in Communities (ARIC)-PET Amyloid Imaging Study showed that an increasing number of midlife vascular risk factors were associated with amyloid deposition, consistent with a role of vascular disease in the development of AD [36].

The reported prevalence of visually assessed amyloid positivity rage from $5 \%$ of (a total of 38) MCI patients assessed 6 months post-stroke [37], to $40 \%$ of (a total of 10) post-stoke dementia patients assessed from 0.5 to 4 years post-stroke [38]. Of the seven studies identified [9, 10, 32, 33, 38, 39], six used the amyloid tracer Pittsburg compound B, one used ${ }^{18}$ F-Flut-PET [37].

In the CAST (Cognition After STroke) study, dementia and mild cognitive impairment (MCI) were diagnosed and sub-classified according to proposed underlying etiology at one- and seven- years post-stroke [40, 41]. In the present sub-study from the CAST cohort, all stroke survivors were offered ${ }^{18} \mathrm{~F}$-Flut-PET at seven-year follow-up. To our knowledge, this is the first study on ${ }^{18}$ F-Flut-PET 7 years post-stroke.

As stroke and AD share a common set of vascular risk factors, and amyloid depositions increases over time [42], we hypothesized that amyloid deposition is common in stroke survivors diagnosed with CI and, further, that quantitatively assessed ${ }^{18}$ F-Flut-PET uptake at 7 years post-stroke correlates with $\mathrm{CSF} A \beta_{42}$ levels at 1 year, and with measures of neurodegeneration and cognition at 7 years.

\section{Methods}

\section{Participants}

All patients with a first-ever TIA or stroke, without known cognitive decline pre-stroke, admitted to the stroke unit at Bærum Hospital between February 2007 and July 2009 were invited to participate in the CAST study. Patients with previous stroke or TIA, subarachnoid hemorrhage, life expectancy of less than 1 year, known cognitive decline as indicated by a score of $\geq 3.44$ on The Informant Questionnaire on Cognitive Decline in the Elderly (IQCODE) [43], or patients who did not speak Norwegian were excluded. Stroke survivors were invited to participate in a follow-up study from February 2014 to July 2016. Details can be found in previous published papers $[40,44]$.

\section{Examinations and assessments}

At baseline, stroke etiology was classified according to the Trial of ORG 10172 (TOAST) classification [45], and patients underwent neuroimaging with computed tomography $(\mathrm{CT})$ and/or magnetic resonance imaging (MRI).

In short, at baseline, at one and at seven-year post-stroke, vascular risk factors, and current medication were recorded. Fasted blood samples and an electrocardiography (ECG), 
were obtained, and body mass index (BMI) was calculated. Neurological impairment was assessed using the National Institutes of Health Stroke Scale (NIHSS) [46]. Cognitive evaluation included the Mini Mental State Examination (MMSE) [47], the clock drawing test [48], the Trail making test part A and B (TMT-A and B) [49], and the 10-word memory test [50]. Additional tests at 7 year post-stroke were the Montreal Cognitive Assessment (MoCA) [51] and Controlled Oral Word Association Test (COWAT) [52]. Global functional outcome was assessed by the modified Rankin Scale (mRS) [53] and personal activities of daily living (p-ADL) by the Barthel Activities of Daily Living Index [53].

Supplementary investigations at one and 7 years included MRI of the brain, carotid ultrasound, and when possible, lumbar puncture was performed. Cerebrospinal fluid (CSF) was collected in polypropylene tubes and immediately transported to the local laboratory, in accordance with the manufacturers' instructions. Biomarkers for neurodegenerative disease (amyloid- $\beta$ peptide $\left(A \beta_{42}\right)$ levels, total tau (T-tau) and phosphorylated tau (P-tau)) were quantified with commercially available ELISAs (Fujirebio Europe, Gent, Belgium). The laboratory recommended a cut-off value of $\mathrm{A} \beta_{42} \leq 550 \mathrm{ng} / \mathrm{L}$ for abnormality, modified from Sjögren et al. [54].

\section{Cerebral MRI}

At one- and seven- years follow-up, MRI scans were acquired on a Philips Intera system 1.5 T (Philips Medical Systems, Best, The Netherlands). The MRI study protocol consisted of 3D-T1, axial T2, 3D-FLAIR, DWI and SWI sequences.

MRI investigations were evaluated for focal vascular lesions, medial temporal lobe atrophy (MTLA), white matter lesions (WML), and global cortical atrophy (GCA), by two radiologists, blinded to the clinical information. Any discrepancies were resolved by consensus. MTLA was graded from 0 to 4 ; with MTLA grade $0=$ no atrophy, MTLA $4=$ highest degree of atrophy. MTLA 01 is considered normal [55]. WML was rated using the visual rating scale proposed by Fazekas, scores ranging from 0 to 3 [56]. GCA was rated using the visual rating scale known as Pasquier scale, ranging from 0 to 3 [57].

\section{MRI segmentations and analyses}

Cortical reconstruction and volumetric segmentation were performed with the FreeSurfer image analysis suite version 6.0.0 (http://surfer.nmr.mgh. harvard.edu/). This includes segmentation of the subcortical white-matter and deep gray-matter volumetric structures [58] and parcellation of the cortical surface [59]. This labels cortical sulci and gyri, and thickness values are calculated in the regions of interest. All segmentations were manually inspected.

\section{${ }^{18} \mathrm{~F}$-Flutemetamol PET CT acquisition}

Seven years post-stroke, patients were examined with a Siemens Biograph40 mCT scanner (Siemens Healthineers, Erlangen, Germany). All patients received an intravenous injection of approximately $185 \mathrm{MBq}{ }^{18} \mathrm{~F}$-Flutemetamol (mean $188 \mathrm{MBq}$, range 165-218 MBq). Image acquisition started approximately $90 \mathrm{~min}$ after injection (mean $91 \mathrm{~min}$, range 78-108) with a low dose CT followed by PET acquisition for 20 min (four frames of 5 minutes). 3D dynamic emission data were obtained with a resolution recovery algorithm with time of flight (TrueX with two iterations, 21 subsets and a Gaussian filter with FWHM of $2 \mathrm{~mm}$, matrix size $400 \times 400$ ). Reconstructed images had a slice thickness of $2 \mathrm{~mm}$ and a voxel size of $2 \times 2 \times 2 \mathrm{~mm}^{3}$.

\section{Qualitative classification of ${ }^{18}$ F-Flutemetamol PET}

${ }^{18} \mathrm{~F}$-Flut PET images were visually classified as positive $\left({ }^{18}\right.$ F-Flut-PET $\left.(+)\right)$ or negative $\left({ }^{18}\right.$ F-Flut-PET $\left.(-)\right)$ by at least two nuclear medicine physicians with experience in ${ }^{18} \mathrm{~F}$-Flut PET, and recorded in patients' medical records in line with standard clinical practice between 2015 and 2017. In addition, one nuclear medicine physician with experience in ${ }^{18} \mathrm{~F}$-Flut PET repeated classification in 2019, and in case of discrepancy between the classifications, an additional expert was consulted. All image classifications were performed according to the validated electronic reader program [60] and as described previously [15].

\section{Quantitative classification of ${ }^{18} \mathrm{~F}$-Flutemetamol PET}

Motion correction of the ${ }^{18} \mathrm{~F}$-Flut PET was performed using frame-by-frame rigid registration, then the frames were summed to a single time-frame image and rigidly registered to the anatomical MRI volume using a 6parameter rigid registration as implemented in the Statistical Parametrical Mapping (SPM 12, Wellcome Trust Centre for Neuroimaging, UCL, UK) toolbox. ${ }^{18}$ F-FlutPET standardized uptake value ratios (SUVr) were obtained by normalization to the brainstem. Both the cerebellar cortex, pons and brainstem are widely used Flutemetamol reference regions, acquiring amyloid build plaques not until the fifth and final phase of amyloid deposition [61]. Our choice of reference region was influenced by local tradition, a feeling that the structural masks of the cerebellar cortex were less accurate, and a long series of publications utilizing the brainstem or pons as reference region. Prior to normalization, the brainstem mask was eroded by $1 \mathrm{~mm}$ to avoid partial volume effects, inaccurate segmentation or coregistration. ${ }^{18}$ F-Flut-PET uptake was analyzed in five 
pre-selected cortical regions of interest (ROIs), as defined by Desikan et al. [62] and implemented in FreeSurfer as described above, known to hold substantial amyloid plaques in $\mathrm{AD}$ : the precuneus and posterior cingulate combined, anterior cingulate, prefrontal, inferior parietal, and lateral temporal cortex [63]. The ${ }^{18} \mathrm{~F}$-FlutPET uptake for each region was averaged across the hemispheres. We further calculated a composite SUVr by averaging the uptake in the above-mentioned regions. SUVr were not calculated to categorize scans as positive or negative but used as continuous variables in correlation analyses.

\section{Outcomes and diagnosis of cognitive function}

The criteria outlined by Winblad et al. [64] were used for $\mathrm{MCI}$, and the International Classification of Diseases 10th revision (ICD-10) criteria [2] for dementia diagnoses at both one and 7 years post-stroke. The diagnoses were made in consensus meetings by two senior neurologists (B.F and B.T) and one senior geriatrician (A.R.Ø). Details of the novel method for sub-classification have previously been reported [41], with six potential subgroups; degenerative $\mathrm{MCI}$ or degenerative dementia, vascular MCI (MCI VaD) or vascular dementia (dementia $\mathrm{VaD}$ ) or mixed degenerative and vascular $\mathrm{MCI}$ or dementia. The evaluations were based on the results from the medical history, cognitive assessments, the IQCODE and information regarding daily functioning. Subclassification for proposed underlying etiology was based on MRI findings of vascular or degenerative brain changes, biomarkers in the CSF, the patient's vascular risk factors and clinical cognitive profile. Patients were classified with possible vascular disease when the radiological findings revealed WMLs without MTLA, while MTLA without WMLs was interpreted as degenerative etiology. Patients with combined pathologies were classified with mixed vascular and degenerative disease.

\section{Statistics}

Categorical variables were compared with Pearson's chisquared test and continuous variables with independent Student t-test. The relationship between death as dependent variable and age-adjusted CSF as independent variables were assessed with logistic regression analyses. Correlation analyses of ${ }^{18}$ F-Flut-PET SUVr and measures of neurodegeneration and cognition, were performed assessing the Pearson correlation coefficient in continuous variables (MTA, CSF A $\beta_{42}$ levels, GCA, TMT-A), Spearman rho in ranked data (MMSE). Linear regression analyses were performed with ${ }^{18} \mathrm{~F}$-Flut-PET SUVr as explanatory variable. Each regression model was adjusted for age. Statistical analyses were performed using SPSS Statistic version 23.

\section{Results}

\section{Study population}

Of the 208 patients included in 2007-2008, 111 completed 7 years follow-up, of whom 26 patients agreed to PET imaging and 13 of these had CSF from 12 months. 12 out of the 26 patients who agreed to PET imaging were diagnosed with $\mathrm{CI}$ at 7 years. In total, 80 patients died during the study period, and 17 were lost to followup for other reasons. A flow chart is presented in Fig. 1. Characteristics and assessments at baseline and 7 years for the complete study population are presented in Table 1. Characteristics and assessment at baseline, clinical cognitive profile and MRI findings at 1 year in stroke survivors by PET or no PET at 7 years are presented in Table 2. Significantly more patients who agreed to PET had normal cognition and lower CSF Ttau at 12 months follow-up. There were no differences regarding age, stroke subtype or assessments at baseline, or MRI findings at 1 year.

\section{Amyloid-binding in stroke survivors}

The main characteristics, MRI, ${ }^{18} \mathrm{~F}$-Flut-PET, and cognitive assessment findings are summarized in (see Additional file 1). Among the 26 patients who agreed to PET, five patients had no MRI at 7 years, required in our quantitative assessment method. Four scans were visually classified ${ }^{18} \mathrm{~F}$-Flut(+). 13 patients were diagnosed with CI (mixed or neurodegenerative disease) at 7 years, one with a positive PET scan. Quantitative ${ }^{18} \mathrm{~F}$-Flut-PET SUVr in different cortical regions is presented in Table 3.

Comparing patients according to normal or $\mathrm{CI}$ at 7 years, no difference in mean SUVr (SD) was observed (0.57 (0.08) vs $0.60(0.18), p=0.54)$. Eight patients changed from normal cognition at 1 year to $\mathrm{CI}$ at 7 years, one of whom was amyloid positive. When comparing cognitive decline to stable cognition during follow-up, no difference in mean SUVr (SD) was observed (0.65 (0.24) vs $0.56(0.07), p=0.16)$. Three of four patients with visually positive PET had normal cognition at 7 years.

Eighty patients died before follow-up, 33 with CSF from 1 year. Logistic regression assessing age-adjusted CSF $A \beta_{42}$ levels and death, did not demonstrate any significant association (OR 1.0, 95\%CI 0.99-1.0). Ageadjusted CSF $\mathrm{T}$-tau was not significantly associated with death (OR 1.0, 95\%CI 1.0-1.0).

\section{Correlations}

${ }^{18}$ F-Flut-PET SUVr at 7 years did not correlate with CSF $\mathrm{A} \beta_{42}$ levels at 1 year $(\mathrm{r}=0.12 ; p=0.703)$, MTLA $(\mathrm{r}=$ $0.10 ; p=0.670)$, GCA $(\mathrm{r}=0.10 ; p=0.652)$ or MMSE $(\mathrm{r}=$ $-0.32 ; p=0.162)$ at 7 years, when adjusted for age. TMT-A at 7 years was significantly correlated to ${ }^{18} \mathrm{~F}$ - 


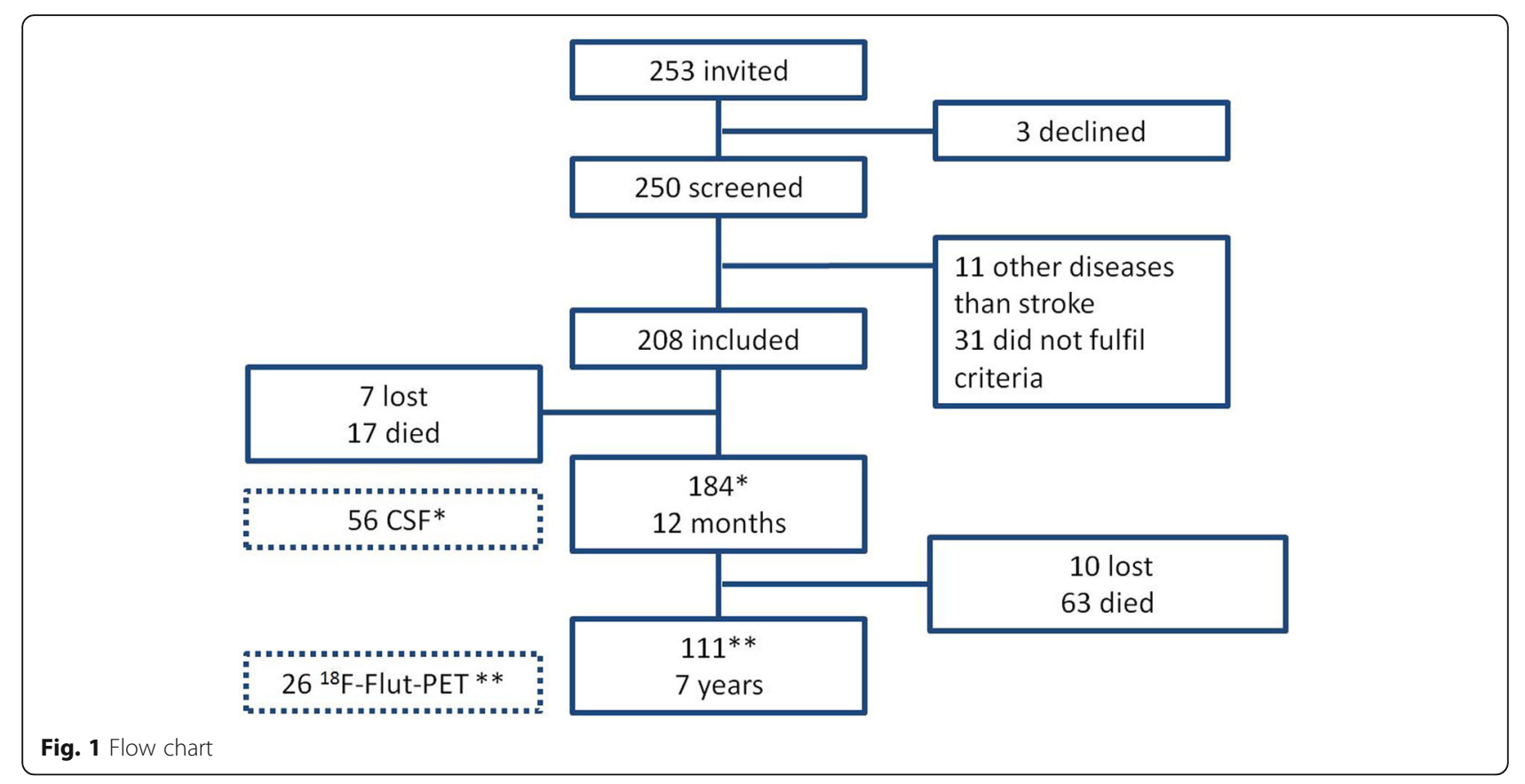

Table 1 Baseline characteristics $(n=208)$ and assessments in survivors at 7 years $(n=111)$

\begin{tabular}{|c|c|c|}
\hline & Baseline & 7-year follow-up \\
\hline $\begin{array}{l}\text { Male (\%) } \\
\text { Mean age, years (SD) } \\
\text { Less than } 9 \text { years of education (\%) }\end{array}$ & $\begin{array}{l}105(51) \\
72.0(12.2) \\
50(24)\end{array}$ & $\begin{array}{l}46(41) \\
75.2(11.2)\end{array}$ \\
\hline \multicolumn{3}{|l|}{ Stroke subtype (\%) } \\
\hline $\begin{array}{l}\text { Cerebral infarction } \\
\text { TIA } \\
\text { Cerebral hemorrhage }\end{array}$ & $\begin{array}{l}164(79) \\
28(14) \\
16(7)\end{array}$ & \\
\hline \multicolumn{3}{|l|}{ Risk factors (\%) } \\
\hline $\begin{array}{l}\text { Hypertension* } \\
\text { Hyperlipidemia } \\
\text { Diabetes } \\
\text { Cigarette smoking (present) } \\
\text { Coronary heart disease } \\
\text { Atrial fibrillation } \\
\text { Daily alcohol use } \\
\text { BMl }>25\end{array}$ & $\begin{array}{l}123(59) \\
117(56) \\
23(11) \\
18(18) \\
45(22) \\
65(31) \\
20(24) \\
119(57)\end{array}$ & \\
\hline \multicolumn{3}{|l|}{ TOAST classification (\%) } \\
\hline $\begin{array}{l}\text { Large-vessel disease } \\
\text { Cardio-embolic disease } \\
\text { Small-vessel disease } \\
\text { Stroke of undetermined etiology }\end{array}$ & $\begin{array}{l}21(10) \\
60(29) \\
64(31) \\
63(30)\end{array}$ & \\
\hline \multicolumn{3}{|l|}{ Assessments. Mean (SD) (n) } \\
\hline \multirow[b]{2}{*}{$\begin{array}{l}\text { IQCODE } \\
\text { MMSE } \\
\text { NIHSS } \\
B 1 \\
\text { MRS } \\
\text { TMT-A } \\
\text { TMT-B } \\
\text { 10-Word test immediate recall } \\
\text { 10-Word test, delayed recall }\end{array}$} & $3.1(0.2)(n=208)$ & \\
\hline & $\begin{array}{l}26.0(4.5)(n=195) \\
2.44(4.6)(n=208) \\
17.5(5.1)(n=208) \\
1.5(1.4)(n=208) \\
73.7(66.7)(n=177) \\
152.8(89.8)(n=152) \\
17.9(2.9)(n=170) \\
4.3(2.5)(n=184)\end{array}$ & $\begin{array}{l}25.8(5.9)(n=109) \\
1.02(2.3)(109) \\
18.7(3.7)(109) \\
1.4(1.3)(109) \\
55.7(39.6)(n=101) \\
126.4(67.7)(n=82) \\
22.5(8)(n=106) \\
4.7(3)(n=105)\end{array}$ \\
\hline
\end{tabular}

$\mathrm{TIA}=$ Transistent Ischemic Attack; Hyperlipidemia $=$ total cholesterol $>5 \mathrm{mmol} / \mathrm{L}$ or $\mathrm{LDL}>3 \mathrm{mmol} / \mathrm{L} ; \mathrm{LDL}=\mathrm{Low}$ Density Lipoprotein; Diabetes $=$ an established diagnosis or Haemoglobin A1C (HbA1C) $\geq 7.0$; Coronary Heart Disease = previous myocardial infarction or present angina pectoris; BMl=Body mass index; TOAST = the trial of org 10,172 in acute stroke treatment classification; NIHSS=National Institute of Health Stroke Scale; BI=Barthel Activities of Daily Living Index; mRS = modified Rankin scale; IQCODE = the informant questionnaire on cognitive decline in the elderly. MMSE = Mini Mental State Examination; $\mathrm{SD}=$ standard deviation. ${ }^{*}$ Hypertension = use of BP lowering drugs at baseline 
Table 2 Characteristics at baseline, clinical cognitive profile and MRI findings at 1 year in stroke survivors by PET or no PET at 7 years

\begin{tabular}{|c|c|c|c|}
\hline & PET & NO PET & $\boldsymbol{P}$ value \\
\hline N & 26 & 85 & \\
\hline Male (\%) & $18(69)$ & $43(51)$ & 0.227 \\
\hline Mean age, years (SD) & $72.9(7.0)$ & $75.9(11.8)$ & 0.239 \\
\hline Less than 9 years of education (\%) & $4(15)$ & $18(21)$ & 0.776 \\
\hline Living alone (\%) & $4(15)$ & $24(28)$ & 0.288 \\
\hline Stroke subtype (\%) & & & 0.926 \\
\hline Cerebral infarction & $20(77)$ & $66(78)$ & \\
\hline $\mathrm{TIA}$ & $4(15)$ & $11(13)$ & \\
\hline Cerebral hemorrhage & $2(8)$ & $8(9)$ & \\
\hline TOAST classification (\%) & & & 0.724 \\
\hline Large-vessel disease & $2(8)$ & $12(14)$ & \\
\hline Cardio-embolic disease & $8(31)$ & $19(22)$ & \\
\hline Small-vessel disease & $9(35)$ & $29(34)$ & \\
\hline Stroke of undetermined etiology & $7(27)$ & $25(30)$ & \\
\hline \multicolumn{4}{|l|}{ Assessments. Mean (SD) (n) } \\
\hline $\mathrm{NIHSS}$ & $1.12(2.1)(26)$ & $1.99(3.6)(85)$ & 0.247 \\
\hline mRS & $1.0(1.2)(26)$ & $1.26(1.2)(85)$ & 0.266 \\
\hline IQCODE & $3.0(0.1)(26)$ & $3.1(0.2)(85)$ & 0.641 \\
\hline MMSE & $27.8(2.1)(26)$ & $26.5(4.0)(82)$ & 0.113 \\
\hline \multicolumn{4}{|l|}{ Clinical profile 12 months } \\
\hline Dementia & $1(26)$ & $13(84)$ & 0.223 \\
\hline $\mathrm{MCl}$ & $6(26)$ & $31(84)$ & 0.286 \\
\hline Normal cognition & $19(26)$ & $40(84)$ & 0.040 \\
\hline \multicolumn{4}{|l|}{ MRI 12 months. Mean (SD) (n) } \\
\hline MTLA grade & $0.79(0.8)(24)$ & $1.18(1.2)(77)$ & 0.135 \\
\hline Fazekas score & $1.52(0.8)(25)$ & $1.86(0.9)(76)$ & 0.095 \\
\hline Global Cortical Atrophy & $1.28(0.7)(25)$ & $1.48(0.6)(75)$ & 0.177 \\
\hline CSF (Aß)-42 (ng/L) 12 months (n) & $840(250)(13)$ & $861(302)(41)$ & 0.824 \\
\hline CSF total tau (ng/L) 12 months (n) & $270(101)(13)$ & $387(192)(41)$ & 0.040 \\
\hline
\end{tabular}

$\mathrm{TIA}=$ Transient Ischemic Attack; TOAST = the trial of org 10,172 in acute stroke treatment classification; NIHSS=National Institute of Health Stroke Scale; BI=Barthel Activities of Daily Living Index; $\mathrm{mRS}=$ modified Rankin scale; IQCODE = the informant questionnaire on cognitive decline in the elderly; MMSE = Mini Mental State Examination; $\mathrm{SD}=$ standard deviation; $\mathrm{MCl}=$ mild cognitive impairment; $\mathrm{MTLA}=$ medial temporal lobe atrophy. $\mathrm{CSF}(\mathrm{A} \beta)-42=$ cerebrospinal fluid amyloid $-\beta$ peptide

Flut-PET SUVr $(\mathrm{r}=0.69 ; p=0.00)$, but exploring data revealed one outlier on the scatterplot, and after exclusion, there was no significant correlation. Associations between composite ${ }^{18}$ F-Flut-PET SUVr and CSF A $\beta_{42}$ levels at 1 year are presented in Fig. 2.

\section{Discussion}

In this cohort, only one patient diagnosed with CI 7 years post stroke was amyloid positive. Quantitatively assessed ${ }^{18} \mathrm{~F}$-Flut-PET did not correlate with amyloid- $\beta$ peptide $\left(A \beta_{42}\right)$ levels in CSF at 1 year or MTLA, GCA, MMSE, or TMT-A at 7 years.

Our findings with only one visually ${ }^{18} \mathrm{~F}$-Flut(+) in post-stroke CI patients $(8 \%)$ are in line with the results from the prospective DEDEMAS study (Determinants of Dementia After stroke), where only 2 out of 38 (5\%) post-stroke $\mathrm{MCI}$ patients had positive amyloid scans. In the DEDEMAS study, neuropsychological testing was performed only 6 months after stroke, theoretically too early to capture amyloid deposition initiated by the stroke. As in our study, only a minor portion of patients completed the PET examination (38/178) [37].

Visual classification of ${ }^{18} \mathrm{~F}$-Flut-PET is still the only validated method for clinical use, however quantification is beneficial to obtain a continuous measure of ${ }^{18} \mathrm{~F}$-FlutPET. One proposed cut-off for quantitatively assessed ${ }^{18} \mathrm{~F}$-Flut-PET using CortexID, with pons as reference region, is SUVr 0.61 [65]. All patients with visually positive 
Table 3 Quantitative ${ }^{18}$ F-Flutemetamol PET SUVr in different cortical regions

\begin{tabular}{|c|c|c|c|c|c|c|}
\hline Cases & precuneus and posterior cingulate combined & anterior cingulate & prefrontal & inferior parietal & lateral temporal & $\begin{array}{l}\text { Composite } \\
\text { SUVr }\end{array}$ \\
\hline 1 & - & - & - & - & - & \\
\hline 2 & - & - & - & - & - & \\
\hline 3 & 0.82 & 0.70 & 0.60 & 0.64 & 0.55 & 0.65 \\
\hline 4 & - & - & - & - & - & \\
\hline 5 & 0.48 & 0.47 & 0.46 & 0.46 & 0.44 & 0.50 \\
\hline 6 & 0.55 & 0.56 & 0.52 & 0.51 & 0.51 & 0.57 \\
\hline 7 & 0.54 & 0.48 & 0.48 & 0.48 & 0.48 & 0.54 \\
\hline 8 & 0.54 & 0.52 & 0.50 & 0.51 & 0.49 & 0.55 \\
\hline 9 & 0.85 & 0.68 & 0.68 & 0.75 & 0.65 & 0.74 \\
\hline 10 & - & - & - & - & - & \\
\hline 11 & 0.52 & 0.51 & 0.49 & 0.49 & 0.48 & 0.54 \\
\hline 12 & 1.24 & 1.21 & 1.21 & 1.14 & 1.16 & 1.13 \\
\hline 13 & 0.54 & 0.49 & 0.50 & 0.51 & 0.49 & 0.55 \\
\hline 14 & - & - & - & - & - & \\
\hline 15 & 0.51 & 0.48 & 0.47 & 0.49 & 0.47 & 0.53 \\
\hline 16 & 0.57 & 0.54 & 0.51 & 0.53 & 0.50 & 0.57 \\
\hline 17 & 0.64 & 0.64 & 0.56 & 0.59 & 0.57 & 0.63 \\
\hline 18 & 0.59 & 0.63 & 0.57 & 0.53 & 0.51 & 0.58 \\
\hline 19 & 0.51 & 0.50 & 0.46 & 0.47 & 0.46 & 0.52 \\
\hline 20 & 0.48 & 0.45 & 0.44 & 0.45 & 0.43 & 0.49 \\
\hline 21 & 0.50 & 0.48 & 0.46 & 0.46 & 0.46 & 0.51 \\
\hline 22 & 0.51 & 0.47 & 0.48 & 0.49 & 0.50 & 0.54 \\
\hline 23 & 0.49 & 0.49 & 0.48 & 0.48 & 0.47 & 0.50 \\
\hline 24 & 0.51 & 0.50 & 0.47 & 0.46 & 0.48 & 0.53 \\
\hline 25 & 0.56 & 0.53 & 0.57 & 0.50 & 0.53 & 0.59 \\
\hline 26 & 0.54 & 0.54 & 0.51 & 0.48 & 0.50 & 0.54 \\
\hline
\end{tabular}

PET in our study had composite SUVr $>0.61$ in line with the cut-off, even though we applied a different software for quantification. Amyloid deposition increases with age [12], and in our cohort the oldest had the highest SUVR and were the only visually PET positive among participants with CI.

Roberts et al. studied the prevalence of PET amyloidpositivity in a non-demented cohort drawn from the general population. They found that amyloid positivity in persons with $\mathrm{MCI}$ ranged from $0 \%$ in the age group $50-59$ to $16 \%$ in participants aged $80-89$ years [12]. Previous studies have reported a slightly higher prevalence between 10 and $30 \%$ in cognitively healthy-people [66, 67]. The frequency of amyloid positivity in our cohort is consistent with the observations from the general population, so no evident stroke-related inflammation with amyloid deposition is observed in our cases. Two cases had larger strokes with NIHSS $\geq 4$ at discharge, both without amyloid positivity after 7 years.
When assessing PET semi- quantitatively, PET SUVr did not differ substantially between cases, and there was no significant difference when comparing those with or without CI, or when comparing those who experienced cognitive decline or stable cognition during follow-up. As our patients were imaged in regular clinical routine, with variable start in image acquisition, we acknowledge that this may affect the SUVr.

Three patients were diagnosed with MCI AD in consensus, none with amyloid positivity. This is in line with a previous study from the CAST cohort, where we found a correlation between pathological cerebrospinal fluid (CSF) concentrations of microtubule-associated protein tau ( $\mathrm{T}$-tau) 1 year post-stroke and brain atrophy, indicating that tau-linked neurodegeneration might be more important than amyloid post-stroke [68]. Recent studies suggest that changes in the blood-brain barrier (BBB) and BBB-mediated neurodegeneration, plays an essential 


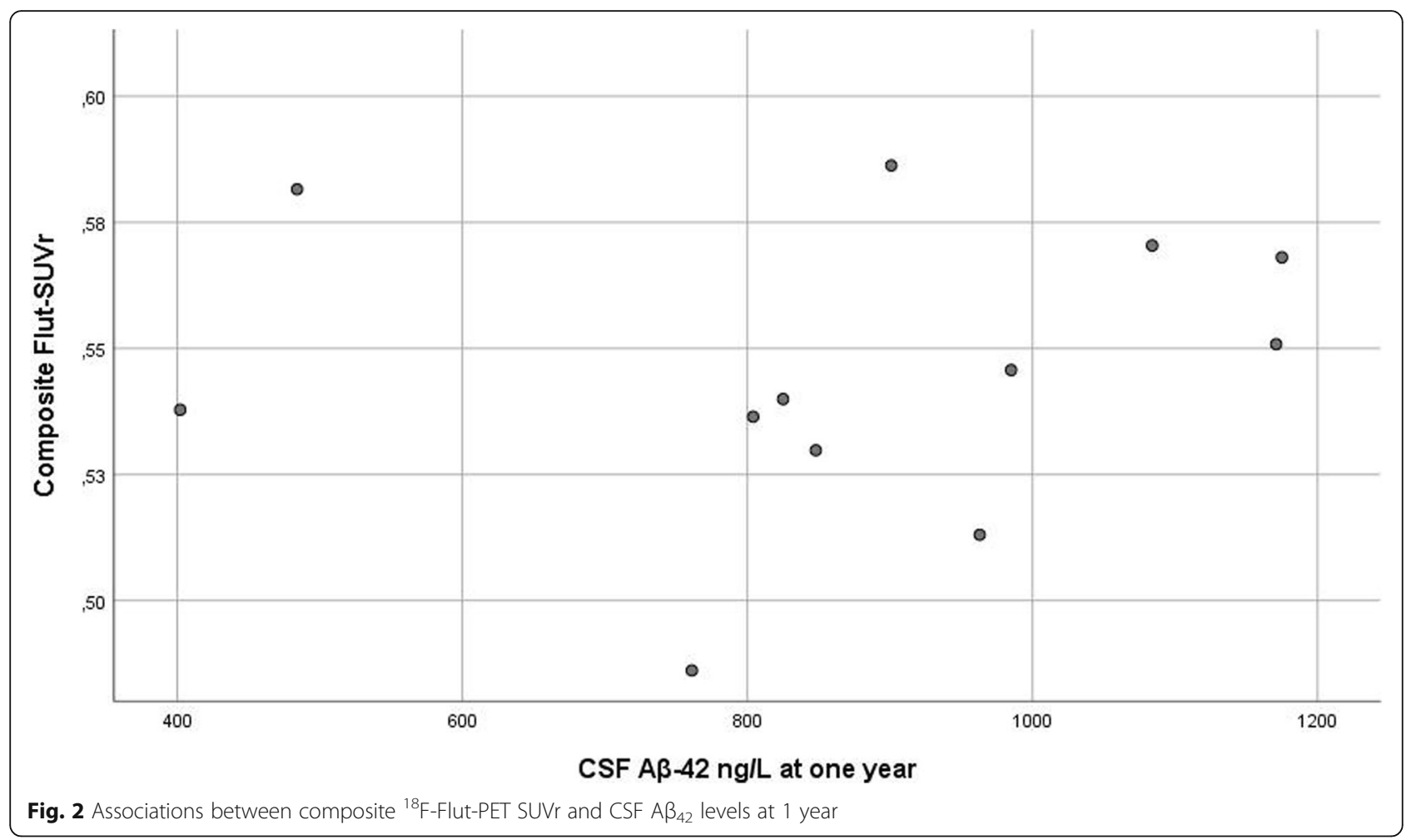

role in cognitive dysfunction independent of $A \beta$ biomarkers $[69,70]$.

In the study by Roberts et al., more amyloid-positive participants died compared to amyloid negative during the 4 year follow-up period, $13 \%$ vs $4.6 \%$ respectively [12]. Death before follow-up might bias our findings, but when assessing the relation between CSF biomarkers at 1 year and prospective mortality using logistic regression analysis, CSF $A \beta_{42}$ at 1 year was not associated with death in our cohort.

As shown in Fig. 2, surprisingly, CSF $A \beta_{42}$ at 1 year did not correlate with PET SUVr at 7 years. Three patients had pathological levels of CSF $A \beta_{42}$ at 1 year, all without amyloid positivity at 7 years. Contrary to CSF T-tau, CSF $A \beta_{42}$ levels remain unchanged after stroke when followed for 6 months [71]. One possible explanation could be that stroke decreases the ability to eliminate amyloid, maybe due to changes in the BBB [72], with normalization after some years. Garcia-Alloza et al. [73] demonstrated $A \beta$ formation in a mice model as a transient phenomenon induced by a stroke, most likely through interference with amyloid clearance pathways. One study with repeated amyloid PET in 21 patients, one and 18 month post-stroke, found a significant reduction in amyloid accumulation in the infarct region, probably caused by a breakdown of BBB in the acute phase, with a leak of the radioactive ligand with "false" high
SUVr [32]. The optimal timing for $A \beta$ assessment poststroke is not known but is essential for the development of future prediction models and individualized management. Due to small numbers, our observations must be confirmed in larger samples and interpreted with caution.

Our study has several limitations. First our limited sample size, as only 56 patients agreed to lumbar puncture at 1 year and 26 to PET after 7 years. Patients on anticoagulation therapy or those unable to consent, were excluded from lumbar puncture due to ethical considerations. This might bias our findings. After 7 years, due to time consuming examinations and long travel distances between hospitals, only highly motivated patients, and more of those with normal cognition at 1 year, agreed to PET, making our findings less generalizable. The strength of our study is the long-term follow-up with the same team of nurses and physicians, and measurement of amyloid at two time points. As far as we know, this is the first study to offer PET examination 7 years poststroke, and by that adding important knowledge to amyloid evaluation post-stroke.

\section{Conclusions}

In conclusion, amyloid binding was not common in our cohort of stroke survivors diagnosed with CI. Assessed 
quantitatively, amyloid load correlates neither with other measures related to neurodegeneration nor with CSF $A \beta_{42}$ at 1 year in this cohort. Therefore, amyloid pathology may not be a key mediator of neurodegeneration 7 years post-stroke. Validations of our findings in larger studies are needed.

\section{Supplementary information}

Supplementary information accompanies this paper at https://doi.org/10. 1186/s12883-020-01753-w.

Additional file 1 : Table 3. Clinical characteristics, imaging features and CSF A $A-42$ of patients with PET examination

\begin{abstract}
Abbreviations
AD : Alzheimer's disease; BMI: Body mass index; CAST: Cognition After STroke; Cl: Cognitive impairment; COWA: Controlled Oral Word Association Test; CSF A $\beta_{42}$ : Amyloid- $\beta$ peptide-42; CSF : Cerebrospinal fluid; CT: Computer tomography; ECG: ECG; GCA: Global cortical atrophy; IQCODE : Informant Questionnaire on Cognitive Decline in the elderly; MCl: Mild cognitive impairment; MMSE : Mini Mental State Examination; MoCA: Montreal Cognitive Assessment; MRI: Magnetic resonance imaging; mRS: Modified Rankin Scale; MTLA: Medial temporal lobe atrophy; NIHSS : National Institutes of Health Stroke Scale; OCSP : Oxfordshire Community Stroke Project classification; p-ADL: Barthel Activities of Daily Living Index; PET: Positron emission tomography: P-tau : Phosphorylated microtubuleassociated protein tau; RCT : Randomized controlled trial; SUVr: Standardized uptake value ratios; TIA : Transient ischemic attack; TOAST : The Trial of Org 10172 in Acute Stroke Treatment; TMT A : Trail Making Test A; TMT B : Trail Making Test B; T-tau : Microtubule-associated protein tau; VaD: Vascular Dementia ; ${ }^{18}$ F-Flut: ${ }^{18}$ F-Flutemetamol
\end{abstract}

\section{Acknowledgements}

Not applicable.

\section{Authors' contributions}

$B F, B T, A R \varnothing, H e l H, T B W$ and $G H$ researched literature and conceived the study. HelH, BF, BT and GH were invoved in the protocol development and gaining ethical approval. $\mathrm{HåH}$, HelH and $\mathrm{GH}$ were involved in patient recruitment. PS, EGM and MB analyzed the patients PET and MRI. GH wrote the first draft of the manuscript. Revision of manuscript for important intellectual content: STP. All authors contributed to data analysis, drafting and revising the article, gave final approval of the version to be published, and agree to be accountable for all aspects of the work.

\section{Funding}

Not applicable.

\section{Availability of data and materials}

The datasets used during the current study are available from the corresponding author on reasonable request.

\section{Ethics approval and consent to participate}

The study was approved by the Regional Committee for Medical and Health Research Ethics South East and by the Data Protection Authorities (2013/ 1829). Written informed consent was obtained from all patients; if the patient was cognitively impaired, relatives also gave their written assent. Patients unable to give consent were excluded from lumbar puncture in line with recommendations from REK.

\section{Consent for publication}

Not applicable.

\section{Competing interests}

Hege Ihle-Hansen is a member of the editorial board in BMC neurology.

\section{Author details}

'Bærum Hospital, Vestre Viken Hospital Trust, N-3004 Drammen, Norway. ${ }^{2}$ Institute of Clinical Medicine, University of Oslo, Oslo, Norway. ${ }^{3}$ Department of Geriatric Medicine, Oslo University Hospital, Oslo, Norway. ${ }^{4}$ Department of Neurology, Department of Internal Medicine, Central Hospital Karlstad and Faculty of Medicine, Örebro University, Örebro, Sweden. ${ }^{5}$ Department of Neurology, Akershus University Hospital, Oslo, Norway. ${ }^{6}$ Division of Radiology, Nuclear Medicine Oslo University Hospital, Oslo, Norway. ${ }^{7}$ Department of Nuclear Medicine, Oslo University Hospital, Oslo, Norway. ${ }^{8}$ Centre for Prevention of Stroke and Dementia, Nuffield Department of Clinical Neurosciences, University of Oxford, Oxford, UK. ${ }^{9}$ NIHR Oxford Biomedical Research Centre, John Radcliffe Hospital, Oxford, UK.

Received: 17 December 2019 Accepted: 29 April 2020

Published online: 08 May 2020

\section{References}

1. Brainin M, Tuomilehto J, Heiss WD, Bornstein NM, Bath PM, Teuschl Y, et al. Post-stroke cognitive decline: an update and perspectives for clinical research. Eur J Neurol. 2015:22(2):229-38 e13-6.

2. Organization WH. The ICD-10 classification of mental and Behavioural disorders: diagnostic criteria for research. Geneva. 1993.

3. Ballard C, Rowan E, Stephens S, Kalaria R, Kenny RA. Prospective follow-up study between 3 and 15 months after stroke: improvements and decline in cognitive function among dementia-free stroke survivors $>75$ years of age. Stroke. 2003:34(10):2440-4.

4. Rasquin SM, Lodder J, Verhey FR. Predictors of reversible mild cognitive impairment after stroke: a 2-year follow-up study. Journal of the neurological sciences. 2005;229-230:21-5.

5. Tang EY, Amiesimaka O, Harrison SL, Green E, Price C, Robinson L, et al. Longitudinal Effect of Stroke on Cognition: A Systematic Review. Journal of the American Heart Association. 2018;7(2)

6. Rothwell PM, Coull AJ, Giles MF, Howard SC, Silver LE, Bull LM, et al. Change in stroke incidence, mortality, case-fatality, severity, and risk factors in Oxfordshire, UK from 1981 to 2004 (Oxford vascular study). Lancet. 2004; 363(9425):1925-33.

7. Kandiah N, Chander RJ, Lin X, Ng A, Poh YY, Cheong CY, et al. Cognitive impairment after mild stroke: development and validation of the SIGNAL2 risk score. Journal of Alzheimer's disease : JAD. 2016:49(4):1169-77.

8. Chander RJ, Lam BYK, Lin X, Ng AYT, Wong APL, Mok VCT, et al. Development and validation of a risk score (CHANGE) for cognitive impairment after ischemic stroke. Sci Rep. 2017;7(1):12441.

9. Yang J, Wong A, Wang Z, Liu W, Au L, Xiong Y, et al. Risk factors for incident dementia after stroke and transient ischemic attack. Alzheimer's \& dementia : the journal of the Alzheimer's Association. 2015;11(1):16-23.

10. Liu W, Wong A, Au L, Yang J, Wang Z, Leung EY, et al. Influence of amyloidbeta on cognitive decline after stroke/transient ischemic attack: three-year longitudinal study. Stroke. 2015:46(11):3074-80.

11. Lopez OL, Klunk WE, Mathis C, Coleman RL, Price J, Becker JT, et al. Amyloid, neurodegeneration, and small vessel disease as predictors of dementia in the oldest-old. Neurology. 2014;83(20):1804-11.

12. Roberts RO, Aakre JA, Kremers WK, Vassilaki M, Knopman DS, Mielke MM, et al. Prevalence and outcomes of amyloid positivity among persons without dementia in a longitudinal. Population-Based Setting JAMA Neurol. 2018;75(8):970-9.

13. van Maurik IS, van der Kall LM, de Wilde A, Bouwman FH, Scheltens P, van Berckel BNM, et al. Added value of amyloid PET in individualized risk predictions for MCl patients. Alzheimer's \& dementia (Amsterdam, Netherlands). 2019:11:529-37.

14. Leuzy A, Savitcheva I, Chiotis K, Lilja J, Andersen P, Bogdanovic N, et al. Clinical impact of [(18)F] flutemetamol PET among memory clinic patients with an unclear diagnosis. Eur J Nucl Med Mol Imaging. 2019;46(6):1276-86.

15. Muller EG, Edwin TH, Stokke C, Navelsaker SS, Babovic A, Bogdanovic N, et al. Amyloid-beta PET-correlation with cerebrospinal fluid biomarkers and prediction of Alzheimer $s$ disease diagnosis in a memory clinic. PLoS One. 2019:14(8):e0221365.

16. Blennow $\mathrm{K}$, Hampel $\mathrm{H}$, Weiner $\mathrm{M}$, Zetterberg $\mathrm{H}$. Cerebrospinal fluid and plasma biomarkers in Alzheimer disease. Nat Rev Neurol. 2010;6(3):131-44.

17. Perani D, Schillaci O, Padovani A, Nobili FM, laccarino L, Della Rosa PA, et al. A survey of FDG- and amyloid-PET imaging in dementia and GRADE analysis. Biomed Res Int. 2014;2014:785039. 
18. Ikonomovic MD, Fantoni ER, Farrar G, Salloway S. Infrequent false positive [(18)F] flutemetamol PET signal is resolved by combined histological assessment of neuritic and diffuse plaques. Alzheimers Res Ther. 2018;10(1): 60.

19. Zhang S, Smailagic N, Hyde C, Noel-Storr AH, Takwoingi Y, McShane R, et al. (11) C-PIB-PET for the early diagnosis of Alzheimer's disease dementia and other dementias in people with mild cognitive impairment (MCl). The Cochrane database of systematic reviews. 2014;7:Cd010386.

20. Palmqvist S, Zetterberg H, Blennow K, Vestberg S, Andreasson U, Brooks DJ, et al. Accuracy of brain amyloid detection in clinical practice using cerebrospinal fluid beta-amyloid 42: a cross-validation study against amyloid positron emission tomography. JAMA Neurol. 2014;71(10):1282-9.

21. Adamczuk K, Schaeverbeke J, Vanderstichele HM, Lilja J, Nelissen N, Van Laere K, et al. Diagnostic value of cerebrospinal fluid Abeta ratios in preclinical Alzheimer's disease. Alzheimers Res Ther. 2015;7(1):75.

22. Hansson O, Seibyl J, Stomrud E, Zetterberg H, Trojanowski JQ, Bittner T, et al. CSF biomarkers of Alzheimer's disease concord with amyloid-beta PET and predict clinical progression: a study of fully automated immunoassays in BioFINDER and ADNI cohorts. Alzheimer's \& dementia : the journal of the Alzheimer's Association. 2018;14(11):1470-81.

23. Whitehead S, Cheng G, Hachinski V, Cechetto DF. Interaction between a rat model of cerebral ischemia and beta-amyloid toxicity: II. Effects of triflusal. Stroke. 2005;36(8):1782-9.

24. Whitehead SN, Hachinski VC, Cechetto DF. Interaction between a rat model of cerebral ischemia and beta-amyloid toxicity: inflammatory responses. Stroke. 2005:36(1):107-12.

25. Amtul Z, Nikolova S, Gao L, Keeley RJ, Bechberger JF, Fisher AL, et al. Comorbid Abeta toxicity and stroke: hippocampal atrophy, pathology, and cognitive deficit. Neurobiol Aging. 2014;35(7):1605-14.

26. Thiel A, Cechetto DF, Heiss WD, Hachinski V, Whitehead SN. Amyloid burden, neuroinflammation, and links to cognitive decline after ischemic stroke. Stroke. 2014;45(9):2825-9.

27. Leys D, Henon H, Mackowiak-Cordoliani MA, Pasquier F. Poststroke dementia. The Lancet Neurology. 2005;4(11):752-9.

28. Fein G, Di Sclafani V, Tanabe J, Cardenas V, Weiner MW, Jagust WJ, et al. Hippocampal and cortical atrophy predict dementia in subcortical ischemic vascular disease. Neurology. 2000;55(11):1626-35.

29. Lee JH, Kim SH, Kim GH, Seo SW, Park HK, Oh SJ, et al. Identification of pure subcortical vascular dementia using 11C-Pittsburgh compound B. Neurology. 2011;77(1):18-25

30. Selnes P, Grambaite R, Rincon M, Bjornerud A, Gjerstad L, Hessen E, et al. Hippocampal complex atrophy in poststroke and mild cognitive impairment. Journal of cerebral blood flow and metabolism : official journal of the International Society of Cerebral Blood Flow and Metabolism. 2015; 35(11):1729-37.

31. Gorelick PB, Scuteri A, Black SE, Decarli C, Greenberg SM, ladecola C, et al. Vascular contributions to cognitive impairment and dementia: a statement for healthcare professionals from the american heart association/american stroke association. Stroke. 2011:42(9):2672-713.

32. Sahathevan $R$, Linden $T$, Villemagne VL, Churilov L, Ly JV, Rowe C, et al. Positron emission tomographic imaging in stroke: cross-sectional and follow-up assessment of amyloid in ischemic stroke. Stroke. 2016;47(1):1139.

33. Yasuno F, Kajimoto K, Ihara M, Taguchi A, Yamamoto A, Fukuda T, et al. Amyloid beta deposition in subcortical stroke patients and effects of educational achievement: a pilot study. International journal of geriatric psychiatry. 2019

34. Kim J, Basak JM, Holtzman DM. The role of apolipoprotein E in Alzheimer's disease. Neuron. 2009;63(3):287-303.

35. al Pe. in press. 2020

36. Gottesman RF, Schneider AL, Zhou Y, Coresh J, Green E, Gupta N, et al Association between midlife vascular risk factors and estimated brain amyloid deposition. Jama. 2017;317(14):1443-50.

37. Wollenweber FA, Darr S, Muller C, Duering M, Buerger K, Zietemann V, et al. Prevalence of amyloid positron emission tomographic positivity in Poststroke mild cognitive impairment. Stroke. 2016;47(10):2645-8.

38. Mok V, Leung EY, Chu W, Chen S, Wong A, Xiong Y, et al. Pittsburgh compound B binding in poststroke dementia. J Neurol Sci. 2010;290(1-2): 135-7.

39. Mok V, Xiong Y, Wong KK, Wong A, Schmidt R, Chu WW, et al. Predictors for cognitive decline in patients with confluent white matter hyperintensities.
Alzheimer's \& dementia : the journal of the Alzheimer's Association. 2012;8(5 Suppl):S96-s103.

40. Hagberg G, Fure B, Thommessen B, Ihle-Hansen H, Oksengard AR, Nygard S, et al. Predictors for favorable cognitive outcome post-stroke: A-seven-year follow-up study. Dement Geriatr Cogn Disord. 2019:1-11.

41. Ihle-Hansen H, Thommessen B, Wyller TB, Engedal K, Oksengard AR, Stenset $\mathrm{V}$, et al. Incidence and subtypes of $\mathrm{MCl}$ and dementia 1 year after first-ever stroke in patients without pre-existing cognitive impairment. Dement Geriatr Cogn Disord. 2011;32(6):401-7.

42. Jack CR Jr, Knopman DS, Jagust WJ, Petersen RC, Weiner MW, Aisen PS, et al. Tracking pathophysiological processes in Alzheimer's disease: an updated hypothetical model of dynamic biomarkers. The Lancet Neurology. 2013;12(2):207-16.

43. Jorm AF, Scott R, Cullen JS, MacKinnon AJ. Performance of the informant questionnaire on cognitive decline in the elderly (IQCODE) as a screening test for dementia. Psychol Med. 1991;21(3):785-90.

44. Hagberg G, Fure B, Sandset EC, Thommessen B, Ihle-Hansen H, Oksengard $A R$, et al. Long-term effects on survival after a 1-year multifactorial vascular risk factor intervention after stroke or TIA: secondary analysis of a randomized controlled trial, a 7-year follow-up study. Vasc Health Risk Manag. 2019;15:11-8.

45. Adams HP Jr, Biller J. Classification of subtypes of ischemic stroke: history of the trial of org 10172 in acute stroke treatment classification. Stroke. 2015: 46(5):e114-7.

46. Goldstein LB, Bertels C, Davis JN. Interrater reliability of the NIH stroke scale. Arch Neurol. 1989:46(6):660-2.

47. Folstein MF, Folstein SE, McHugh PR. "mini-mental state". A practical method for grading the cognitive state of patients for the clinician. J Psychiatr Res. 1975;12(3):189-98.

48. Eddy JR, Sriram S. Clock-drawing and telling time as diagnostic aids. Neurology. 1977;27(6):595.

49. RM R. Validity of the trail making test as an indicator of organic brain damage. Percept Mot Skills 1958;8:271-276.

50. Randolph C, Tierney MC, Mohr E, Chase TN. The repeatable battery for the assessment of neuropsychological status (RBANS): preliminary clinical validity. J Clin Exp Neuropsychol. 1998;20(3):310-9.

51. Nasreddine ZS, Phillips NA, Bedirian V, Charbonneau S, Whitehead V, Collin I, et al. The Montreal cognitive assessment, MoCA: a brief screening tool for mild cognitive impairment. J Am Geriatr Soc. 2005;53(4):695-9.

52. Barry D, Bates ME, Labouvie E. FAS and CFL forms of verbal fluency differ in difficulty: a meta-analytic study. Appl Neuropsychol. 2008;15(2):97-106.

53. Sulter G, Steen C, De Keyser J. Use of the Barthel index and modified Rankin scale in acute stroke trials. Stroke. 1999;30(8):1538-41.

54. Sjogren $M$, Vanderstichele $H$, Agren $H$, Zachrisson O, Edsbagge M, Wikkelso

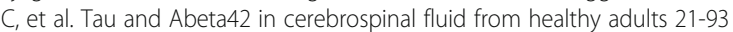
years of age: establishment of reference values. Clin Chem. 2001;47(10): 1776-81.

55. Scheltens $P$, Weinstein HC, Leys D. Neuro-imaging in the diagnosis of Alzheimer's disease. I. Computer tomography and magnetic resonance imaging. Clin Neurol Neurosurg. 1992;94(4):277-89.

56. Pantoni L, Basile AM, Pracucci G, Asplund K, Bogousslavsky J, Chabriat H, et al. Impact of age-related cerebral white matter changes on the transition to disability -- the LADIS study: rationale, design and methodology. Neuroepidemiology. 2005;24(1-2):51-62.

57. Pasquier F, Leys D, Weerts JG, Mounier-Vehier F, Barkhof F, Scheltens P. Inter- and intraobserver reproducibility of cerebral atrophy assessment on MRI scans with hemispheric infarcts. Eur Neurol. 1996;36(5):268-72.

58. Fischl B, Salat DH, Busa E, Albert M, Dieterich M, Haselgrove C, et al. Whole brain segmentation: automated labeling of neuroanatomical structures in the human brain. Neuron. 2002;33(3):341-55.

59. Chincarini A, Peira E, Morbelli S, Pardini M, Bauckneht M, Arbizu J, et al. Semi-quantification and grading of amyloid PET: a project of the European Alzheimer's disease consortium (EADC). Neurolmage Clinical. 2019;23: 101846.

60. Buckley CJ, Sherwin PF, Smith AP, Wolber J, Weick SM, Brooks DJ. Validation of an electronic image reader training programme for interpretation of [18F] flutemetamol beta-amyloid PET brain images. Nucl Med Commun. 2017:38(3):234-41.

61. Thal DR, Rub U, Orantes M, Braak H. Phases of a beta-deposition in the human brain and its relevance for the development of AD. Neurology. 2002; 58(12):1791-800. 
62. Desikan RS, Segonne F, Fischl B, Quinn BT, Dickerson BC, Blacker D, et al. An automated labeling system for subdividing the human cerebral cortex on MRI scans into gyral based regions of interest. Neurolmage. 2006;31(3):96880.

63. Thal DR, Attems J, Ewers M. Spreading of amyloid, tau, and microvascular pathology in Alzheimer's disease: findings from neuropathological and neuroimaging studies. Journal of Alzheimer's disease : JAD. 2014;42(Suppl 4):S421-9.

64. Winblad B, Palmer K, Kivipelto M, Jelic V, Fratiglioni L, Wahlund LO, et al. Mild cognitive impairment--beyond controversies, towards a consensus: report of the international working group on mild cognitive impairment. $J$ Intern Med. 2004;256(3):240-6.

65. Thurfjell L, Lilja J, Lundqvist R, Buckley C, Smith A, Vandenberghe R, et al. Automated quantification of $18 \mathrm{~F}$-flutemetamol PET activity for categorizing scans as negative or positive for brain amyloid: concordance with visual image reads. Journal of nuclear medicine : official publication, Society of Nuclear Medicine. 2014;55(10):1623-8.

66. Petersen RC, Wiste HJ, Weigand SD, Rocca WA, Roberts RO, Mielke MM, et al. Association of Elevated Amyloid Levels with Cognition and Biomarkers in cognitively Normal people from the community. JAMA Neurol. 2016; 73(1):85-92.

67. Jansen WJ, Ossenkoppele R, Knol DL, Tijms BM, Scheltens P, Verhey FR, et al. Prevalence of cerebral amyloid pathology in persons without dementia: a meta-analysis. Jama. 2015;313(19):1924-38.

68. Logallo N, Novotny V, Assmus J, Kvistad CE, Alteheld L, Ronning OM, et al. Tenecteplase versus alteplase for management of acute ischaemic stroke (NOR-TEST): a phase 3, randomised, open-label, blinded endpoint trial. The Lancet Neurology. 2017;16(10):781-8.

69. Nation DA, Sweeney MD, Montagne A, Sagare AP, D'Orazio LM, Pachicano $M$, et al. Blood-brain barrier breakdown is an early biomarker of human cognitive dysfunction. Nat Med. 2019;25(2):270-6.

70. Zhao Z, Nelson AR, Betsholtz C, Zlokovic BV. Establishment and dysfunction of the blood-brain barrier. Cell. 2015;163(5):1064-78.

71. Hesse C, Rosengren L, Vanmechelen E, Vanderstichele H, Jensen C, Davidsson P, et al. Cerebrospinal fluid markers for Alzheimer's disease evaluated after acute ischemic stroke. Journal of Alzheimer's disease : JAD. 2000:2(3-4):199-206.

72. Tarasoff-Conway JM, Carare RO, Osorio RS, Glodzik L, Butler T, Fieremans E, et al. Clearance systems in the brain-implications for Alzheimer disease. Nat Rev Neurol. 2015;11(8):457-70.

73. Garcia-Alloza M, Gregory J, Kuchibhotla KV, Fine S, Wei Y, Ayata C, et al. Cerebrovascular lesions induce transient beta-amyloid deposition. Brain : a journal of neurology. 2011;134(Pt 12):3697-707.

\section{Publisher's Note}

Springer Nature remains neutral with regard to jurisdictional claims in published maps and institutional affiliations.

Ready to submit your research? Choose BMC and benefit from:

- fast, convenient online submission

- thorough peer review by experienced researchers in your field

- rapid publication on acceptance

- support for research data, including large and complex data types

- gold Open Access which fosters wider collaboration and increased citations

- maximum visibility for your research: over $100 \mathrm{M}$ website views per year

At BMC, research is always in progress.

Learn more biomedcentral.com/submissions 